\title{
PERSPECTIVE
}

\section{Targeting oncogenic Ras}

\author{
Ernesto Diaz-Flores and Kevin Shannon ${ }^{1}$ \\ Department of Pediatrics, University of California, San Francisco, California 94143, USA
}

Reversing the consequences of oncogenic Ras is a fundamental problem in cancer therapeutics. Somatic $R A S$ mutations are highly prevalent in many human cancers that respond poorly to current treatments, including carcinomas of the lung, pancreas, and colon; melanoma; and myeloid leukemia (for review, see Schubbert et al. 2007). At first glance, oncogenic Ras is an appealing target for rational drug discovery as the mutant protein is a membrane-associated signaling molecule that is expressed at robust levels in primary tumor cells. However, targeting oncogenic Ras is extremely challenging in practice due to the nature of the Ras cycle and the functional consequences of oncogenic mutations (for review, see Vetter and Wittinghofer 2001; Downward 2003). Ras relies on an intrinsic GTPase activity to terminate signaling by hydrolyzing GTP to GDP. This "off" reaction is relatively inefficient, but is accelerated thousands of fold by the GTPase-activating proteins (GAPs) neurofibromin and p120 GAP, which stabilize a transition state between Ras-GTP and Ras-GDP. Cancer-associated amino acid substitutions at codons 12,13 , and 61 both impair intrinsic Ras GTPase activity and confer resistance to GAPs. In principle, an effective small molecule therapy must therefore restore enzymatic activity within a highly constrained phosphate-binding loop of the oncoprotein without deregulating normal Ras or related cellular GTPases. Given these grim biochemical realities, drug discovery efforts have primarily focused in two areas: (1) blocking enzymes such as farnesyl transferase, which catalyze post-translational modifications of Ras that are essential for membrane targeting; and (2) developing inhibitors of downstream kinases such as MEK, $\mathrm{Akt}$, and mTOR. Inherent in these strategies is the notion that reversing the growth of Ras-driven malignancies inevitably requires interrupting aberrant cell-intrinsic signaling networks. However, despite substantial effort, there are currently no agents that effectively counter the biochemical consequences of oncogenic Ras. A provocative paper by Ancrile et al. (2007) in the July 15 issue of Genes and Development suggests that interfering with the ability of Ras-driven tumors to modulate the behaviors of other cells in the microenvironment could represent a viable therapeutic approach.

${ }^{1}$ Corresponding author.

E-MAIL shannonk@peds.ucsf.edu; FAX (415) 502-5127.

Article is online at http://www.genesdev.org/cgi/doi/10.1101/gad.1587907.
The current work was inspired, in part, by a previous study showing that HRAS-transformed HeLa cells secrete the cytokine interleukin 8 (IL8), which contributes to tumor growth in immunodeficient mice by promoting angiogenesis (Sparmann and Bar-Sagi 2004), and by the reports of elevated levels of another cytokine, interleukin 6 (IL6), in the sera of patients with pancreatic cancer (Wigmore et al. 2002). Ancrile et al. (2007) harnessed a tractable system for transforming primary cells with a defined set of genes that includes SV40 T/t antigens, the telomerase catalytic subunit hTERT, the p110 isoform of phosphoinositide-3-OH (PI-3) kinase fused to a CAAX membrane localization sequence, and a regulatable HRAS ${ }^{G 12 V}$ oncogene (Lim and Counter 2005). Inducing $\mathrm{H}-\mathrm{Ras}^{\mathrm{G} 12 \mathrm{~V}}$ protein expression resulted in morphologic transformation and a tumorigenic phenotype, which was associated with dramatic up-regulation of IL6 production in multiple cell types. Moreover, reducing IL6 levels through the use of short hairpin RNA (shRNA) knockdown technology markedly attenuated tumorigenesis in vivo. Interestingly, Ancrile et al. (2007) present data that argue strongly against autocrine signaling as the reason that IL6 enhances tumor growth. Instead, the data support a paracrine mechanism through which tumor-produced IL6 acts on infiltrating cells in the tissue microenvironment (see Fig. 1). In related studies, these authors observed attenuated tumor formation in IL6 mutant mice that are exposed to a well-established model of skin carcinogenesis. They also showed that IL6 knockdown altered the growth of kidney and mesenchymal cancer cell lines. These experiments support the general principle of targeting the microenvironment as a strategy for inhibiting the growth of tumors expressing oncogenic Ras. This idea is consistent with elegant studies of Schwann cell tumorigenesis in Nf1 mutant mice. The Nf1 tumor suppressor gene encodes neurofibromin, a GAP for Ras, and inactivating this gene in the Schwann cell lineage deregulates Ras signaling and results in tumor formation, which is dependent on aberrant cytokine signaling between the tumor and infiltrating haploinsufficient mast cells (Zhu et al. 2002; Yang et al. 2003).

The data of Ancrile et al. (2007) also raise new questions. First, it is uncertain how oncogenic Ras expression induces IL6 production and, in particular, whether this is consequence of activating Ras/Raf/MEK/ERK, Ral-GDS, PI3 kinase/Akt, and/or other effectors of Ras-GTP. Second, whereas IL6 production by tumorigenic cells is as- 
Figure 1. Model for the effects of IL6 production by HRas mutant tumor cells and effects on the microenvironment. The tumor (green cells) produces IL6 (yellow), which diffuses into the surrounding stroma and activates receptors expressed on infiltrating cells (pink). The identity of these intermediary cells is uncertain, but they could be epithelial cells, $\mathrm{T}$ lymphocytes, myeloid cells, and/or dendritic cells. This IL6-responsive population might produce soluble factors that directly stimulate tumor growth (blue arrow). These cells might also express cell surface proteins (green bar) and/or produce soluble factors (green circles) that recruit endothelial cells (orange) into the microenvironment. Endothelial cells, in turn, could contribute to tumor growth either by feedback activation of tumor cells (orange arrow) and/or by releasing angiogenic factors (short red arrows) that promote blood vessel formation around the tumor.

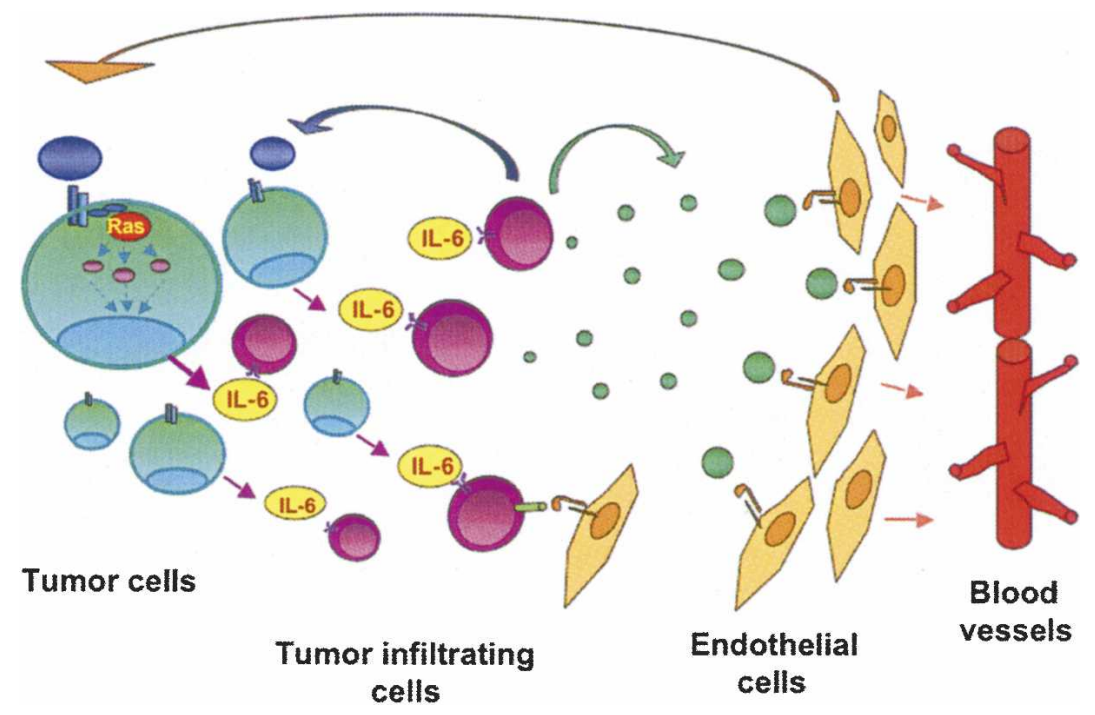

sociated with a marked increase in the number of intratumoral endothelial cells, these cells are not known to express the IL6 receptor. This suggests that an intermediary population of IL6-responsive cells recruits endothelial cells (and perhaps other cell types) into the evolving tumor, and that these infiltrating cells promote the growth of the tumor mass by either overcoming negative regulatory factors and/or by producing molecules that directly or indirectly stimulate growth (Fig. 1). Understanding this complex interplay between tumor-produced IL6 and the microenvironment and, in turn, identifying Ras-dependent and Ras-independent pathways within the tumor that are subsequently activated by infiltrating IL6-responsive normal cells may uncover tractable therapeutic targets. Finally, the data presented in this work largely focuses on the role of IL6 in tumor initiation. Regrettably, human cancers are not diagnosed until much later in the natural history of the disease and a sine qua non for an effective therapeutic is the ability to induce objective regression of established disease. Along these lines, it will be important to investigate if inhibiting IL6 signaling in advanced tumors is efficacious in animal models and, if this approach appears promising, in clinical trials.

\section{Oncogenic Ras: meek or macho?}

Ras occupies a high position in the pantheon of oncoproteins-diabolically activated with the ability to potently deregulate multiple effector molecules and cellular processes. This traditional view, which is largely based on observations made in immortalized cancer cell lines, has gradually given way to a more nuanced understanding that emphasizes cell context and the capacity of primary cells to adapt to the stress of oncogenic Ras protein expression by remodeling signaling networks and adopting alternate fates such as senescence. Moreover, insights from cancer and developmental genetics infer that sub- stantial gaps in our knowledge remain, which have important therapeutic implications. The availability of accurate mouse models that now allow investigators to interrogate the genetic, cell biologic, and biochemical consequences of ablating one or more Ras alleles has provided provocative insights. For example, inactivating one normal Kras allele was shown to greatly accelerate the penetrance and aggressiveness of lung cancer in mice exposed to a mutagen that induces a high frequency of Kras point mutations (Zhang et al. 2001). Based on our understanding of Ras biochemistry, this result is unexpected, as oncogenic K-Ras should confer a dominant cellular phenotype irrespective of the presence or absence of the normal protein. Yet the genetics indicates that the normal K-Ras protein matters and somehow restrains the deleterious effects of its mutant sibling. Another major advance was the development of strains of "knock-in" mice that were engineered to conditionally express oncogenic $\mathrm{K}-\mathrm{Ras}^{\mathrm{G} 12 \mathrm{D}}$ from the endogenous Kras promoter. Remarkably, biochemical investigation of primary cell lineages from these animals revealed little or no activation of downstream effector signaling pathways even in the presence of elevated levels of Ras-GTP (Guerra et al. 2003; Braun et al. 2004; Tuveson et al. 2004). However, despite the apparent ability of normal cells to moderate the downstream consequences of hyperactive Ras, these mice are strongly predisposed to the development of fatal pancreatic, lung, and hematologic cancers (Guerra et al. 2003; Hingorani et al. 2003; Braun et al. 2004; Tuveson et al. 2004).

A most surprising recent discovery was that $H R A S$ and KRAS mutations are tolerated in the germline and underlie disorders of the Noonan syndrome spectrum (for review, see Schubbert et al. 2007). These conditions, which include Noonan, Costello, and cardio-facio-cutaneous syndromes, are characterized by facial abnormalities, heart defects, and impaired growth and development. The germline KRAS mutations found in these individuals introduce novel amino acid substitutions that 
are not found in cancer and encode K-Ras proteins that display intermediate biochemical and functional properties (i.e., they are less activated than oncogenic K-Ras, but deregulated compared with the wild-type protein) (Niihori et al. 2006; Schubbert et al. 2006). Cancer is uncommon in Noonan syndrome, although affected infants frequently demonstrate a spectrum of hematologic abnormalities, and occasionally develop juvenile myelomonocytic leukemia (for review, see Lauchle et al. 2006). In contrast, the germline HRAS mutations found in Costello syndrome, which almost invariably alter codons 12 and 13, also occur as somatic mutations in cancer (Aoki et al. 2005). Remarkably, persons with Costello syndrome are not exceptionally cancer prone. The tissues that are perturbed developmentally (nervous system, musculoskeletal system) overlap with the types of malignancies that are observed (rhabdomyosarcoma, neuroblastoma, ganglioneuroblastoma, and bladder cancer). These data suggest that endogenous levels of activated $\mathrm{H}$-Ras are only transforming in the context of certain tissues or the gene is expressed at low levels in most types of cancer-initiating cells. HRAS mutations account for $<1 \%$ of all cancer-associated RAS mutations. The observation that many individuals with Costello syndrome never develop cancer supports the idea that mutant HRAS requires cooperating mutations for tumorigenesis. Interestingly, loss or silencing of the normal HRAS allele has been reported in some of the malignancies that arise in Costello syndrome patients. It is remarkable that epithelial cancers that show a high incidence of KRAS mutations have not been reported in persons with either Noonan or Costello syndrome. Whereas genetic ablation of either Nras or Hras is compatible with normal development, homozygous Kras mutant embryos succumb in utero (Johnson et al. 1997; Koera et al. 1997; Esteban et al. 2001). If KRAS is the most important isoform for controlling developmental programs, it logically follows that it would be activated by somatic mutation in cancer cells far more often than either HRAS or NRAS. Together, recent observations in genetically engineered mice and human patients underscore the intimate interrelationship of development and cancer, and infer that most normal cell types have a remarkable capacity to tolerate hyperactive Ras signaling without deleterious phenotypic consequences. This is the "meek" side of oncogenic Ras. However, the same "macho" oncoprotein somehow overcomes the best efforts to contain it, and ultimately contributes to about a third of all human cancers. Understanding how cells respond acutely to the stress of oncogenic Ras expression and how these adaptive responses are subverted in cancer have emerged as central questions in the field.

\section{Oncogenic Ras in context}

A persistent theme in understanding the biology of Ras in normal and malignant cells is the immense specificity conferred by specific growth factor/receptor interactions, the dose and duration of signaling, and different roles of the H-Ras, K-Ras, and N-Ras isoforms (for review, see
Marshall 1995; Downward 2006). Translating this complexity into better treatments for cancers with $R A S$ gene mutations will require maintaining a healthy degree of skepticism about any particular result with an awareness of the potential limitations of specific experimental systems. Investigators will need to integrate data from human tumors, mouse models, and cell lines. The clinic is always a good place to begin. Any analysis of oncogenic Ras in cancer leads to the inexorable conclusion that there is something special about KRAS. The reason for this is uncertain, although emerging evidence supports the idea that differences within the C-terminal hypervariable domains have profound effects on signal output from different subcellular compartments (for review, see Mor and Philips 2006). While it is uncertain why primary human cancers frequently mutate $K R A S$, sometimes mutate NRAS, and rarely mutate HRAS, the implications for developing and testing new therapeutic strategies are clear-the isoform matters. Provocative data that are obtained with oncogenic H-Ras or N-Ras should be extended to K-Ras wherever possible. These studies are best carried out in a primary tissue context such as the pancreas where somatic KRAS mutations are common, and should ideally exploit a system in which oncogenic K-Ras is expressed from the endogenous promoter. Along these lines, investigators who are studying the biology of melanoma or myeloid leukemia might consider models driven by NRAS, as this isoform is commonly mutated in these cancers. Patients can also provide clues about treatment strategies. For example, the observation that effector pathways in primary murine cancers that are initiated by K-Ras ${ }^{\mathrm{G} 12 \mathrm{D}}$ expression continue to respond robustly to cytokine growth factors raises the possibility of therapeutically targeting proteins upstream of Ras-GTP. However, genetic analysis of lung tumors from patients who received small molecule inhibitors of the epidermal growth factor receptor showed that oncogenic KRAS mutations were predictive of treatment failure (Pao et al. 2005). As additional targeted agents are tested clinically, correlating $R A S$ mutation status with treatment responses should illuminate general principles for inhibiting oncogenic Ras in different tumor contexts. Well-designed preclinical trials in genetically engineered mice and biochemical analysis of tumors from these animals will also help to define both the architecture of Ras signaling networks in primary cells and potential approaches for achieving a beneficial therapeutic index in vivo. Finally, data from animal models should be integrated with high throughput analysis in well-defined panels of cancer cell lines. Although these studies must be interpreted with caution due to potential artifacts from adaptation to life on plastic and the lack of supporting stromal cells, looking across many cell lines can reveal general patterns such as the dependence of BRAF mutant cells, but not KRAS mutant cells, on MEK signaling (Solit et al. 2005).

After three decades and thousands of reports, the Ras field remains as dynamic and unsettled as ever. Oncogenic Ras represents both a tantalizing target and formidable obstacle to decreasing the burden of cancer 
throughout the world. Together, the development of many small molecules against aberrant signaling molecules, the possibility of modulating the tumor microenvironment, and the availability of new tools for interrogating oncogenic Ras in primary cells hold out promise for substantial advances in the next few years.

\section{Acknowledgments}

We apologize to authors whose work we were not able to cite due to format restrictions. We are indebted to Jennifer Lauchle and David Tuveson for helpful conversations. The work in our laboratory addressing hyperactive Ras signaling in cancer is supported by NIH grants CA72614 and CA104282, by a Leukemia and Lymphoma Society SCOR award, and by the Department of Defense Neurofibromatosis Research Program. E.D.-F. is the recipient of a Young Investigator Award from the Children's Tumor Foundation.

\section{References}

Ancrile, B., Lim, K.-H., and Counter, C.M. 2007. Oncogenic Ras-induced secretion of IL6 is required for tumorigenesis. Genes \& Dev. 21: 1714-1719.

Aoki, Y., Niihori, T., Kawame, H., Kurosawa, K., Ohashi, H., Tanaka, Y., Filocamo, M., Kato, K., Suzuki, Y., Kure, S., et al. 2005. Germline mutations in HRAS proto-oncogene cause Costello syndrome. Nat. Genet. 37: 1038-1040.

Braun, B.S., Tuveson, D.A., Kong, N., Le, D.T., Kogan, S.C., Rozmus, J., Le Beau, M.M., Jacks, T.E., and Shannon, K.M. 2004. Somatic activation of oncogenic Kras in hematopoietic cells initiates a rapidly fatal myeloproliferative disorder. Proc. Nat1. Acad. Sci. 101: 597-602.

Downward, J. 2003. Targeting RAS signalling pathways in cancer therapy. Nat. Rev. Cancer 3: 11-22.

Downward, J. 2006. Signal transduction. Prelude to an anniversary for the RAS oncogene. Science 314: 433-434.

Esteban, L.M., Vicario-Abejon, C., Fernandez-Salguero, P., Fernandez-Medarde, A., Swaminathan, N., Yienger, K., Lopez, E., Malumbres, M., McKay, R., Ward, J.M., et al. 2001. Targeted genomic disruption of $\mathrm{H}$-ras and $\mathrm{N}$-ras, individually or in combination, reveals the dispensability of both loci for mouse growth and development. Mol. Cell Biol. 21: 14441452.

Guerra, C., Mijimolle, N., Dhawahir, A., Dubus, P., Barradas, M., Serrano, M., Campuzano, V., and Barbacid, M. 2003. Tumor induction by an endogenous K-ras oncogene is highly dependent on cellular context. Cancer Cell 4: 111-120.

Hingorani, S.R., Petricoin, E.F., Maitra, A., Rajapakse, V., King, C., Jacobetz, M.A., Ross, S., Conrads, T.P., Veenstra, T.D., Hitt, B.A., et al. 2003. Preinvasive and invasive ductal pancreatic cancer and its early detection in the mouse. Cancer Cell 4: 437-450.

Johnson, L., Greenbaum, D., Cichowski, K., Mercer, K., Murphy, E., Schmitt, E., Bronson, R.T., Umanoff, H., Edelmann, W., Kucherlapati, R., et al. 1997. K-ras is an essential gene in the mouse with partial functional overlap with N-ras. Genes \& Dev. 11: 2468-2481.

Koera, K., Nakamura, K., Nakao, K., Miyoshi, J., Toyoshima, K., Hatta, T., Otani, H., Aiba, A., and Katsuki, M., 1997. K-ras is essential for the development of the mouse embryo. Oncogene 15: 1151-1159.

Lauchle, J.O., Braun, B.S., Loh, M.L., and Shannon, K. 2006. Inherited predispositions and hyperactive Ras in myeloid leukemogenesis. Pediatr. Blood Cancer 46: 579-585.

Lim, K.H. and Counter, C.M. 2005. Reduction in the requirement of oncogenic Ras signaling to activation of PI3K/AKT pathway during tumor maintenance. Cancer Cell 8: 381392.

Marshall, C. 1995. Specificity of receptor tyrosine kinase signaling: Transient versus sustained extracellular signal-regulated kinase activation. Cell 80: 179-185.

Mor, A. and Philips, M.R. 2006. Compartmentalized Ras/MAPK signaling. Annu. Rev. Immunol. 24: 771-800.

Niihori, T., Aoki, Y., Narumi, Y., Neri, G., Cave, H., Verloes, A., Okamoto, N., Hennekam, R.C., Gillessen-Kaesbach, G., Wieczorek, D., et al. 2006. Germline KRAS and BRAF mutations in cardio-facio-cutaneous syndrome. Nat. Genet. 38: 294-296.

Pao, W., Wang, T.Y., Riely, G.J., Miller, V.A., Pan, Q., Ladanyi, M., Zakowski, M.F., Heelan, R.T., Kris, M.G., and Varmus, H.E. 2005. KRAS mutations and primary resistance of lung adenocarcinomas to gefitinib or erlotinib. PLoS Med. 2: e17. doi: 10.1371/journal.pmed.0020017.

Schubbert, S., Zenker, M., Rowe, S.L., Boll, S., Klein, C., Bollag, G., van der Burgt, I., Musante, L., Kalscheuer, V., Wehner, L.E., et al. 2006. Germline KRAS mutations cause Noonan syndrome. Nat. Genet. 38: 331-336.

Schubbert, S., Shannon, K., and Bollag, G. 2007. Hyperactive Ras in developmental disorders and cancer. Nat. Rev. Cancer 7: 295-308.

Solit, D.B., Garraway, L.A., Pratilas, C.A., Sawai, A., Getz, G., Basso, A., Ye, Q., Lobo, J.M., She, Y., Osman, I., et al. 2005. BRAF mutation predicts sensitivity to MEK inhibition. $\mathrm{Na}$ ture 439: 358-362.

Sparmann, A. and Bar-Sagi, D. 2004. Ras-induced interleukin-8 expression plays a critical role in tumor growth and angiogenesis. Cancer Cell 6: 447-458.

Tuveson, D.A., Shaw, A.T., Willis, N.A., Silver, D.P., Jackson, E.L., Chang, S., Mercer, K.L., Grochow, R., Hock, H., Crowley, D., et al. 2004. Endogenous oncogenic K-ras ${ }^{\mathrm{G} 12 \mathrm{D}}$ stimulates proliferation and widespread neoplastic and developmental defects. Cancer Cell 5: 375-387.

Vetter, I.R. and Wittinghofer, A. 2001. The guanine nucleotidebinding switch in three dimensions. Science 294: 12991304.

Wigmore, S.J., Fearon, K.C., Sangster, K., Maingay, J.P., Garden, O.J., and Ross, J.A. 2002. Cytokine regulation of constitutive production of interleukin-8 and -6 by human pancreatic cancer cell lines and serum cytokine concentrations in patients with pancreatic cancer. Int. J. Oncol. 21: 881-886.

Yang, F.C., Ingram, D.A., Chen, S., Hingtgen, C.M., Ratner, N., Monk, K.R., Clegg, T., White, H., Mead, L., Wenning, M.J., et al. 2003. Neurofibromin-deficient Schwann cells secrete a potent migratory stimulus for $\mathrm{Nf1}^{+/-}$mast cells. J. Clin. Invest. 112: 1851-1861.

Zhang, Z., Wang, Y., Vikis, H.G., Johnson, L., Liu, G., Li, J., Anderson, M.W., Sills, R.C., Hong, H.L., Devereux, T.R., et al. 2001. Wildtype Kras2 can inhibit lung carcinogenesis in mice. Nat. Genet. 29: 25-33.

Zhu, Y., Ghosh, P., Charnay, P., Burns, D.K., and Parada, L.F. 2002. Neurofibromas in NF1: Schwann cell origin and role of tumor environment. Science 296: 920-922. 


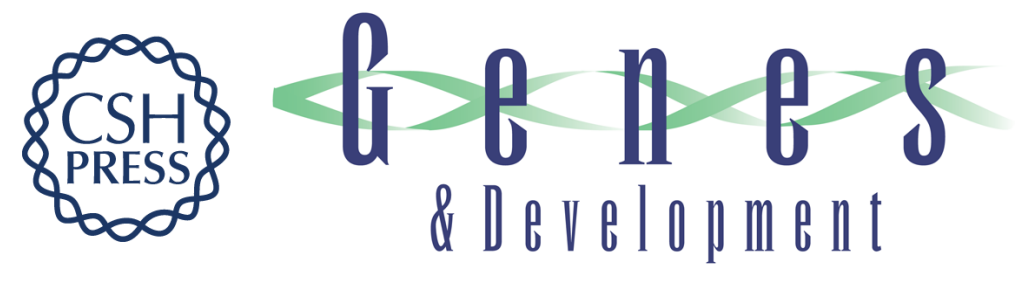

\section{Targeting oncogenic Ras}

Ernesto Diaz-Flores and Kevin Shannon

Genes Dev. 2007, 21:

Access the most recent version at doi:10.1101/gad.1587907

Related Content Oncogenic Ras-induced secretion of IL6 is required for tumorigenesis

Brooke Ancrile, Kian-Huat Lim and Christopher M. Counter

Genes Dev. July , 2007 21: 1714-1719

References This article cites 26 articles, 7 of which can be accessed free at:

http://genesdev.cshlp.org/content/21/16/1989.full.html\#ref-list-1

Articles cited in:

http://genesdev.cshlp.org/content/21/16/1989.full.html\#related-urls

\section{License}

Email Alerting

Receive free email alerts when new articles cite this article - sign up in the box at the top Service right corner of the article or click here.

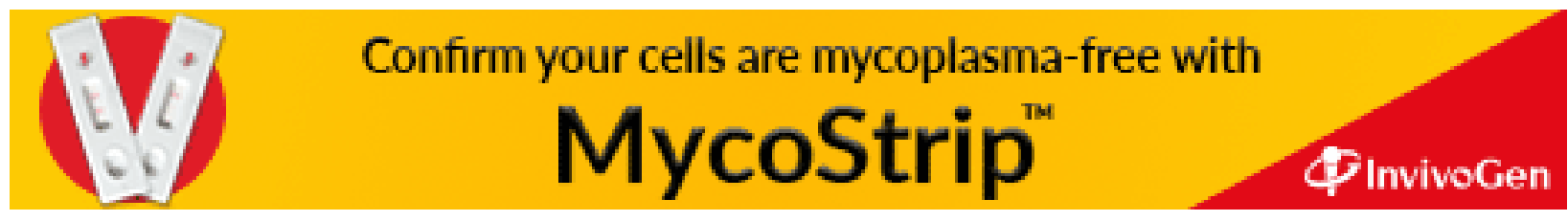

